\title{
4. PROPOSALS REGARDING WORK STRATEGIES IN PLASTIC VISUAL ACTIVITIES III. DEVELOPING THE CREATIVE BEHAVIOR
}

\author{
Ana-Maria Aprotosoaie-Iftimi ${ }^{248}$
}

\begin{abstract}
Contemporary psychologist Didier Anzieu ${ }^{249}$ speaks of five phases of the process of creation: creative emotion, gaining consciousness, transposition, elaboration, and exposure. Each of the five phases has a correspondent in the stages of development of visual-plastic educational activities, and the role of the teacher is essential in each of them. Starting from the five phases, we propose an approach pattern to the creative process, adapted and developed during the years of experience in pre-university educational environment, and refined throughout the research activity carried out in the university environment.
\end{abstract}

Key words: creative process, creative behavior, vizual art teacher, creative child

\section{A. Establishing a relationship with the self}

Establishing a relationship with oneself and "deepening oneself" corresponds to regression or the creative emotion. Each of us looks for a quiet place, away from the crowd's noise, where one feels comfortable, where one retires as into a protective cocoon. The artist, through the creative process, is capable of regression, escape and self-denial, through fluctuations between the inner and outer world. In this sense, the archetypal representations associated with the feeling of entering into a relationship with something essential are also involved. Thinking through abstract concepts is abandoned in favor of figurative thinking and expression through concrete images and effects that will fix the subject of the visual representation. In the dialogue with students, the teacher can use his or her childhood memories, personal experiences in this regard. A method to provide a teaching material that is always available can be done by creating a personal museum that encourages the student's regressive attitude. All children have an affectionate attraction towards certain objects that they attach to their thoughts and feelings; everybody likes to gather objects and to keep starting from the early years of their lives. Encouraging this practice at older ages as well, we can establish a relationship between the interests of the child and the creative productions we engage him/her in. Creating a personal museum (a collection of objects, things, images that he loves, which he/she feels attached to in one way or another), the young person will be stimulated in a different manner, he/she will perceive differently the surroundings and he/she will be

\footnotetext{
${ }^{248}$ Lecturer PhD., "George Enescu" National University of Arts from Iaşi, Romania, email: anamariaiftimi@gmail.com

${ }^{249}$ Anzieu Didier, Le corps de l'œuvre, Gallimard, Bibliothèque de l'inconscient, Paris,1981, pag. 377.
} 
encouraged to build his/her own culture, which will be a treasure, a place of refuge. Over the years, this museum can be enriched, thus becoming a genuine intimate space, the expression of the direct and indirect relationship between the child/the adult and the world. Thus, it is possible to collect reproductions, illustrations, photographs, drawings, sketches and other objects centered around a theme, an event, that will allow for more openings, more dynamism, the possibility to seek refuge, to evolve and so on. The exchange of ideas, verbal exchanges between the student and the teacher or colleagues based on the existence of a personal museum allow, up to a certain extent, to perceive their own interests. At this stage, in the school environment, the teacher tries to create an atmosphere of calm, tranquility, an atmosphere that facilitates the awakening of dormant creative emotions. This is amplified by the tone of voice and an encouraging attitude, through color images, music, etc.

\section{B. Establishing a relationship with the outside world}

Establishing a relationships with the outside world can coincide with the stage of enlightnment or of the rising awareness on the unconscious mental representations.

- Fantomatic figurative expressions become acknowledged and they get set as a guideline. It is the stage in which the young creator doubts, is in full search, forgets his/her own identity, is absorbed entirely by his/her work, identifies himself/herself with it, has an animated consciousness of things, and needs a positive illusion. At this stage one can find the positive role of the teacher through constant encouragement and support in the searches made by the students. Children should be encouraged to get involved as much as possible in what they do, to create works to represent them and that are done only by them, without help or the teacher's intervention.

- For the artist, the surrounding objects/things are not singular but they are perceived as being determined by a universal order whose key is to be discovered. When painting a landscape, he/she really represents nature as a whole, and when he/she represents a scene with characters, he/she actually depiscts a certain level of representation of culture. Thus, the way in which things are represented is no longer part of the ordinary sphere, obtaining a superior status. At this point, the creative child can be encouraged to observe and reflect on the things that surround him/her and on the peculiarities and relationships between them.

- The artist sees what nobody has seen yet. He is an opportunist, a collector, but also an inventor, a person who transforms things: a common, ordinary thing becomes a subject of admiration. The child can be encouraged to consider several possibilities: to draw sketches, to write notes, to write/sketch his/her own thoughts, to process previous sketches, to modify the original objects destructuring, recomposition, etc. 


\section{Establishing relationships within the activity}

Establishing relationships within the activity would coincide with the stages of transposition and development, proposed by contemporary psychologist Didier Anzieu.

- Man can not live on this earth without leaving in one way or another a trace of his existence; therefore, he builds and/or modifies nature. Starting from an object/idea, the artist is an architect that organizes the raw material based oninternal laws, rules dictated by his own geometry. The creative child is at the stage in which he/she has to be encouraged to make/do something all the time, alone or in collaboration with someone else (each child can make a part of the whole, which will then be associated with another part from a colleague in order to achieve a collective object).

- Transposition involves establishing a code and painting a representation. The artist chooses the materials, the support to give shape to the artistic expression. At this stage, the role of the teacher is to facilitate the students' expression. The choice of the materials should remain open and not be imposed or directed by the teacher. The teacher should leave the situation sufficiently open for the student to have the impression that he/she gets to choose the means he/she agrees.

- Elaboration involves the proper realization of the work, in the smallest detail, until the author considers it to be finished. In all the things we perceive we seek an idea, we need logic, a thread that guides us to decrypt the world around us. Around all the points of reference that we have, there are established relationships between the elements determined by the orientation of the forms, rehearsals, analogies. The artist uses various procedures to direct the reading of his own creation. Thus, the space of the work, regardless of the adopted technique, is organized and viewed / perceived from left to right, from top to bottom. The role of the teacher is to facilitate the work environment by removing the stimuli that can disturb the field of vision. The child, during creation, must be encouraged and guided to ensure continuity between elements, to complete the work.

\section{Establishing relationships with others}

Establishing relationships with others or exposure is the time when the artist makes his creation known. Having certain qualities recognised motivates action. For the artist, there are reasons and ways to seduce the audience, forcing it to stop and come closer, to attract its attention with the aim of making it interested, even if that interest produces pleasure or shock. Opening the heart, expressing opinions means that the taken measure has attracted attention. The child must understand and feel that his artistic production matters and therefore that he/she, as a being, counts through his/her creation. The child needs the teacher's remarks and it is desirable that he/she encourages every creative and imaginative effort, however small and insignificant it may seem. 
After the artist has attracted attention through his creation, someone will lshow interest. It is the moment when the artist welcomes the spectator without telling him/her everything, letting him/her understand that there are things that have not yet been discovered, so the spectator is compelled to see what the artist wants to show. The child can be encouraged to express their own ideas about the work, what he/she wanted to do - to stir curiosity, to express himself/herself in a personal manner - even if those ideas may seem curious or impossible, fantastic.

- In order to attract the attention of the adult, the child knows how to draw attention, thoughts, to capture them. It's just like in the case of some artworks, masterpieces, or those portraits that seem to be watching us in any direction we move. Images attract, they cause emotions. The images that make time stop are those that will fascinate the spectator in one way or another. The artist wants to keep the spectator in front of his work. It is the stage that involves presenting children's work, giving value through exposure. It is the stage in which the teacher makes collective or personal exhibitions with the works of young creators, facilitates the knowledge of students' works to a wider audience colleagues, teachers, parents, community, etc.

\section{Conclusions}

Art is essential in the formation of the contemporary man, even if art education is often considered not to be "practical" by the teachers teaching scientific, technical or theoretical subjects, by parents, and often by the community. Because of this, art did not integrate satisfactorily into the list of school disciplines. In schools, the predominant learning model is the traditional one, based on the scientific approach, the artistic discipline in school should be considered as an essential creative factor of personal evolution, as a discipline of mediating all knowledge and of forming basic cultural competences. Regarding these ways of approaching and organizing the didactic activities at the visualplastic education classes, they were commented with the interested students, during the years, during specialized seminars. Later, students were encouraged to develop and address these opportunities in pedagogical practice activities supported by the didactic training program.

\section{References}

1. Addison, Nicholas, Burgess Lesley, (2007), Learning to Teach Art and Design in the Secondary School. A Companion to School Experience. Second Edition, London and New York. Routledge Taylor \& Francis Group., London.

2. A.V.I., S.A.P., (2007), Periferic 7. Focussing Iași/Social Processes. International Biennial for Contemporary Art, Asociația Vector Iași \& Siemens Arts Program, Editura Polirom și Revolver, Iași.

3. Charman, Helen; Rose, Katherine; Wilson, Gillian, (2006), The Art Gallery Handbook. A Resource for Teachers, Tate Publishing, London, UK. 
4. Clement, Robert, Thomas, (1993), The Art teacher's Handbook. Second Edition, Stanley Thornes (Publishers) Ltd., London, U.K..

5. C.I.S.R., D.T.E., (2016), Review of Artistic Education. No. 11-12/2016, Center of Intercultural Studies and Research, Department for Teachers Education, "George Enescu" University of Arts, Iași, Artes Publishing House, Iași.

6. Dowing, Dick; Watson, Ruth, (2004), School art: What's in it? Exploring Visual Arts in Secondary Schools, National Foundation of Educational Research, London, UK.

7. Hegyi, Dora; László, Zsuzsa, (coord.), (2008), Periferic 8 - Art as Gift. Biennial for Contemporary Art, Editura Grup Mușatinii, Suceava.

8. Hickman, Richard, (2000), Art Education 11-18. 2nd Edition, Continuum, London and New York.

9. Holm, Anna, Marie, (2005), The Art Club- a journey with experiment and enthusiasm, Herning: Av form, Denmark.

10. Isaksen, Scott G., et.al., (1994), The assessment of creativity: An occasional paper from the creativity based information resources project, New York: Center for Studies in Creativity, Buffalo, S.U.A..

11. Lindauer, Martin S., (1998), Interdisciplinarity, the Psychology of Art and Creativity: an Introduction, în Creativity Research Journal, vol.11, nr.1, 1998, p.10.

12. Rayment, Trevor, 2007), The Problem of Assesment in Art and Design, Intellect Books, Bristol, U.K..

13. Weintraub, Linda, (2003), Making contemporary art. How today's artists think and work, London. Tames \&Hudson.

14. Wilson, Simon, Lack, Jessica, (2008), The Tate Guide to Modern Art Terms, London: Tate Publishing Ltd.

15. Wright, Peter, (2009), Teaching in Arts Education, in Saha Lawrence J. \& Dworkin Gary (Ed.), International Handbook of Research on Teachers and Teaching, Editura Springer International Handbooks of Education, Volume 21, 2009 , p. $1029-1040$. 